\title{
Multilobar Electrocorticography Monitoring During Intracranial Aneurysm Surgery
}

\author{
A. R. Dehdashti, ${ }^{1, *}$ E. Pralong, ${ }^{2}$ D. Debatisse, ${ }^{2}$ and L. Regli' \\ 'Department of Neurosurgery and 'Division of Neurophysiology, CHUV, Lausanne, Switzerland
}

\begin{abstract}
Introduction: To detect a neuronal threshold of tolerance to ischemia, the usefulness of multilobar electrocorticography $(\mathrm{mEcoG})$ during intracranial aneurysm surgery was compared to the scalp EEG and correlated with the postoperative neurological status and the radiological findings.

Methods: Twenty-one patients harboring intracranial aneurysms were monitored by simultaneous scalp EEG and lobe-dependent $m E c o G$ during surgical clipping. The patients were divided into group A ( 6 patients with no temporary clipping) and group B (15 patients with temporary clipping).

Results: New focal modifications of the mEcoG signal with high frequency (HF)- $\beta 3$ and delta waves were observed in none of the patients in group A and all of the patients in group B. These anomalies were followed by focal burst suppression pattern in eight cases $(53 \%)$ in group B. These changes were detected in only two cases $(9 \%)$ on the scalp EEG. New corticographic changes resolved in eight patients (53\%) in group B. Among the seven patients in group B who had persistent focal burst pattern after clip removal, six (85\%) presented with new neurological deficit or new hypodensity on CT. The Glasgow Outcome Scale was good (IV or V) in $85 \%$ of cases.

Conclusion: $\mathrm{mEcoG}$ is more sensitive than scalp EEG. The appearance and persistence of the focal burst suppression pattern shown on mEcoG, was associated with a new neurological deficit or new hypodensity, whereas HF- $\beta 3$ or delta waves per se were not associated with new changes. A better comprehension of these EEG anomalies could determine the duration of temporary clipping and consequently influence the surgical strategy.
\end{abstract}

Key Words: Neuromonitoring; electroencephalography; corticography; aneurysm surgery; ischemia.

(Neurocrit. Care 2006;04:215-222)

\section{*Correspondence and reprint requests to:}

Amir R. Dehdashti, Department of Neurosurgery, CHUV, 46 Rue de Bugnon, 1011, Lausanne, Switzerland.

E-mail: amir.dehdashti@chuv.ch

\section{Humana Press}

\section{Introduction}

Cerebral neuromonitoring includes all the techniques allowing immediate detection of events prone to cause brain damage and is used in intracranial vascular surgery. The neuromonitoring should (1) identify events at a reversible stage, (2) confirm that these events actually interfere with central or peripheral nervous system integrity, and (3) measure the metabolic disturbances of nervous dysfunction. It is important to note that the outcomes of these three approaches are not necessarily correlated with each other and it is even from their convergences or discrepancies that additional useful information can be extracted for optimal patient management (1,2). Temporary vascular occlusions may be necessary during aneurysm surgery. Real-time detection 
of cerebral ischemia during surgical repair of intracranial aneurysms could be extremely helpful to the surgeon in determining the duration of tolerance for temporary vascular occlusion (3-6). We recently published a report evaluating the feasibility and sensitivity of intraoperative multilobar electrocorticography (mEcoG) during vascular surgery and identified EEG patterns that could yield ischemic events during temporary vascular occlusion (7).

Somatosensory evoked potentials (SSEPs) $(6,8,9)$, motorevoked potentials (MEP) (10-12), and scalp EEG $(13,14)$ are the most common neuromonitoring techniques. The value of SSEPs has been investigated in a large number of patients and responses were found to change in roughly $20 \%$ of surgical procedures, although there is a significant incidence of false negative results $(6,16-18)$. The MEP was studied in a few series and shown to provide advantage for detecting ischemic insults along the motor pathway, but the positive effect on patient outcome still needs to be confirmed. Changes in the scalp EEG show limited sensitivity, with estimates that 5 to $40 \%$ of patients show significant changes $(13,14)$. Monolobar EcoG recordings $(2,15)$ have also been performed, but there is insufficient data to evaluate the overall sensitivity of this technique.

The purpose of neurophysiological monitoring with $\mathrm{mEcoG}$ is to improve the detection of neuronal threshold of tolerance to ischemia. The results of our feasibility study with $\mathrm{mEcoG}$ showed EEG pattern variations during temporary diffusing in $95 \%$ of patients. The purpose of the current study is to correlate the EEG pattern variations appearing during temporary clipping with postoperative clinical and radiological status in a consecutive series of patients with intracranial aneurysms.

\section{Methods}

The method has been described in detail elsewhere (7). Briefly, preoperative monitoring with scalp EEG and mEcoG was performed in 21 patients undergoing microsurgical clipping of 23 intracranial aneurysms (21 aneurysms in the anterior circulation and 2 on the basilar bifurcation).

\section{Preoperative Clinical Condition}

Thirteen patients had ruptured aneurysms. Eleven were in a good clinical condition (World Federation of Neurosurgeons Grading System [WFNS] I or II). Two were in poor clinical grade (WFNS V). Eight patients had 10 asymptomatic unruptured aneurysms.

\section{Anesthesia Management}

Anesthesia induction was performed using propofol to reduce the cerebral blood volume. After dural opening, the anesthesia was shifted to sevoflurane and remyfentanyl in order to reduce pharmacologically induced EEG high frequency (HF)$\beta 3$ waves and bursts and to reach a constant background EEG (4). If there were any surgical contraindications to this type of anesthesia (e.g., brain swelling during the operation), the anesthesia was switched again to propofol.

\section{Monitoring}

A Micromed digital EEG system with 32 channels was used. The signal was acquired at $256 \mathrm{~Hz}$ and visualized using a bandpass filter between 0.3 and $100 \mathrm{~Hz}$. Surface EEG gain was 50 or $100 \mu \mathrm{V} / \mathrm{cm}$ and mEcoG was 200 or $400 \mu \mathrm{V}$ Ground
(G1) and reference electrode (G2) were positioned in A1/A2. All patients had a preoperative baseline EEG in the operating room. Before surgery scalp electrodes were positioned in FP1FP2 and CP3-CP4, allowing monitoring of anesthesia and intraoperative baseline scalp EEG.

\section{Surgery}

Patients underwent a standard peritonal craniotomy to expose the region of interest. After dural opening, three subdural monopolar electrodes were positioned on the frontal (fEcoG), temporal (tEcoG), and parietal (pEcoG) lobes. Online monitoring was therefore performed with seven leads: four scalp EEG (two ipsilateral and two contralateral electrodes), and three ipsilateral electrodes for EcoG. The placement of subdural electrodes adds an additional 5 minutes to the surgical time and there was no need to enlarge the size of the craniotomy. To reduce electrical artifacts, the wires were stapled to the operative field and a new ground electrode (G1) shifted to the temporal muscle.

Patients were divided into group A (no temporary clipping) and group B (with temporary clipping). In patients undergoing temporary clipping, increase of systemic arterial tension was always induced (+20\% of MAP).

All aneurysms were excluded by clipping. Postoperative angiography demonstrated complete obliteration of 22 of the 23 treated aneurysms (95\% complete obliteration rate). A 2-mm dog ear remnant was identified in one case with a 12-mm posteriorly projecting basilar bifurcation aneurysm. Postoperative evaluation was recorded using the worst neurological status and brain CT in the early phase (48-72 hours), as well as the Glasgow Outcome Scale (GOS) at 3 months (19). The modification of $\mathrm{mEcoG}$ did not lead to corrective strategy during surgery.

\section{Results}

Table 1 shows a summary of patients' characteristics with electrophysiological findings before and after temporary clipping as well as clinical/radiological evaluation.

\section{Electrophysiological Results}

In all patients, good scalp and corticographic EEG signals were recorded.

\section{Group A}

In six patients no temporary clipping was performed. Baseline anomalies with HF- $\beta 3$ waves were present in two cases (patients 2 and 4). An old cerebrovascular accident was the reason in one patient and severe $\mathrm{SAH}$ was the reason for the other. Two patients presented new electrophysiological changes by HF- $\beta 3$ waves and delta waves (patients 1 and 5). These changes were followed by a diffuse (not focal) burst suppression pattern. Both were pharmacological in origin caused by propofol administration. These propofol-induced abnormalities were reversible. The scalp EEG showed in only one case a burst pattern, which also resolved.

\section{Group B}

Temporary clipping was performed for 15 cases. Ten of them had multiple episodes of temporary clipping. The mean duration of temporary clipping was 8 minutes (median $=10$, range $1-80$ minutes). Four patients had baseline anomalies characterized by 
HF- $\beta 3$ waves (patients $7,9,17,21$ ), which were caused by the initial cerebral hemorrhage in three of them. The reason for the other patient was not clear. After temporary clipping, all patients $(100 \%)$ presented focal modifications of the EcoG pattern characterized by HF- $\beta 3$ waves. In 12 cases $(80 \%)$, these HF- $\beta 3$ waves were followed by delta waves, which progressed to focal burst suppression pattern in 8 cases (53\%). These waves were not detected on scalp EEG except in one case in whom only the final burst suppression pattern was identified (Table 2).

The electrophysiological changes resolved in 8 patients out of $15(53 \%)$ after removal of the temporary clip.

The $\mathrm{mEcoG}$ changes persisted in 7 cases (47\%) after clip removal. All presented the transition of HF- $\beta 3$ waves to delta waves and then to focal burst suppression pattern.

\section{Postoperative Neurological Status and Patient Outcomes}

During early postoperative clinical evaluation, 17 of 21 patients $(81 \%)$ exhibited no change or improvement, compared with their preoperative neurological condition. Three patients demonstrated new neurological deficits and one patient died. Among these four patients (patients 7, 14, 16, 17), one had a new left-sided hemiparesis after clipping of a large carotid bifurcation aneurysm, probably caused by a perforator injury. This patient, however, showed dramatic clinical improvement at 3 months with GOS V. One patient showed an anterograde amnesia after clipping of a ruptured AcomA aneurysm caused by the temporary clipping of a dominant A1 segment. The GOS was IV at 3 months. One patient presented a ruptured fusiform aneurysm of the anterior choroidal artery in which the artery had to be sacrificed. The GOS was III at 3 months. One patient with a poor initial WFNS grade (V) caused by a ruptured middle cerebral artery (MCA) aneurysm with a large intracerebral hemorrhage died a few days after surgery because of the severity of initial lesions. This patient had temporary clipping of the MCA during surgery. It was impossible to assess the clinical change in this case because of the severity of initial condition. Overall, 18 patients $(85 \%)$ experienced good outcomes (GOS IV or V) (Table 3).

\section{Radiological Results}

Early postoperative CT was performed within $48 \mathrm{~h}$ and showed new abnormalities in six cases, all from group B (40\%). In two cases, fronto-basal hypodensities were identified related to brain retraction, both clinically asymptomatic. In two cases, ischemic lesions in the internal capsule were shown (one anterior choroidal sacrifice and one lenticulostriate injury). In one case, a caudate nucleus ischemia was observed, which was related to the temporary clipping of A1 segment, and finally, in one case with a poor WFNS grade (V), the postoperative CT showed MCA territory ischemia related to severe initial hemorrhage, intracranial hypertension, and the temporary clipping.

\section{Correlation Between Clinical Outcome Radiological Findings and Neuromonitoring Data}

In group A (6 patients), there were neither new neurological deficits nor new CT abnormalities. The only mEcoG abnor- malities seen during surgery were two cases with pharmacologically induced burst and two with anomalies at baseline. The anomalies caused by propofol were totally reversible, but the anomalies that were present at baseline monitoring persisted throughout surgery.

In group B (15 patients), nine cases showed no new neurological deficit or CT abnormality. Neuromonitoring showed HF- $\beta 3$ waves in all during temporary clipping, which progressed to delta waves in seven cases $(77 \%)$. The transition to focal burst pattern was observed in two cases (22\%). All mEcoG anomalies were reversible after clip removal except for one that had progressed to focal burst pattern (patient 12). In patient 12 , mEcoG changes up to burst suppression pattern were observed during temporary clipping and persisted after the clip removal. In spite of this, he had no new neurological deficit or radiological hypodensity postoperatively (false-positive). There was no clear explanation for the persistence of these anomalies.

Four cases $(27 \%)$ had new neurological deficit and CT hypodensities (patients 7, 14, 16,17), whereas two had asymptomatic new CT hypodensities (patients 8 and 19). The mEcoGs have shown the appearance of HF- $\beta 3$ waves and progression to delta waves and focal burst suppression pattern in all $(100 \%)$. The burst pattern persisted after temporary clipping in all of the patients and was irreversible. There was a clear correlation between the temporary clipping inducing irreversible $\mathrm{mEcoG}$ anomalies (focal burst pattern) after clip removal and the postoperative new neurological deficit or CT hypodensity, although the number of cases was too small to reach any statistical significance.

\section{Analysis of Our Results}

Our results showed that HF- $\beta 3$, delta waves, and burst pattern are not seen in patients without temporary clipping unless there is preexisting brain damage or pharmacologically induced burst pattern. In cases with preexisting baseline anomalies, the $\mathrm{mEcoG}$ monitoring during temporary clipping is less valuable, but any change or progression to delta waves or focal burst pattern could be considered as significant.

In all cases undergoing temporary clipping, arterial occlusion was followed by appearance of EEG signal changes in mEcoG.

$\mathrm{mEcoG}$ changes with focal burst pattern persisted, after clip removal in seven cases in group B (47\%) (Table 4).

In four patients with baseline anomalies (only HF- $\beta 3$ waves), the EEG signals changed during temporary clipping and progressed to delta and focal burst patterns, which persisted in two patients (patients 7 and 17) after clip removal.

There was a positive correlation between the temporary clipping and the appearance of HF- $\beta 3$ waves, delta waves, and focal burst suppression pattern.

The appearance of focal burst suppression pattern during the procedure and remaining after temporary clip removal was associated with the presence of new postoperative neurological deficit or ischemic lesions on postoperative CT. No new neurological deficit was observed in cases without $\mathrm{mEcoG}$ changes or those who presented only HF- $\beta 3$ or delta waves during temporary clipping. 
Summary of Patients Characteristics With Scalp EEG and mEcoG Findings Before and After Temporary Clipping and After

Table 1

\begin{tabular}{|c|c|c|c|c|c|c|c|c|}
\hline Patient & Age & $\begin{array}{l}\text { Aneurysm } \\
\text { location }\end{array}$ & Ruptured & Temporary clip & $\begin{array}{l}\text { Duration } \\
\text { (minutes) }\end{array}$ & $\begin{array}{c}\text { Scalp EEG } \\
\text { before clipping }\end{array}$ & $\begin{array}{c}\text { EcoG before } \\
\text { Oclipping }\end{array}$ & $\begin{array}{c}\text { EcoG (HF waves) } \\
\text { after temporary } \\
\text { clipping }\end{array}$ \\
\hline 1 & 46 & MCA & no & no & 0 & 0 & 0 & 1 \\
\hline 2 & 49 & AcoA & yes & no & 0 & 0 & 1 & 1 \\
\hline 3 & 35 & MCA & no & no & 0 & 0 & 0 & 0 \\
\hline 4 & 46 & BT, MCA & no & no & 0 & 0 & 1 & 1 \\
\hline 5 & 59 & BT & yes & no & 0 & 1 & 0 & 1 \\
\hline 6 & 60 & 2MCA, PcoA & no & no & 0 & 0 & 0 & 0 \\
\hline 7 & 70 & AchA & yes & ICA post-Pcom & 1 & 1 & 1 & 1 \\
\hline 8 & 54 & Pericallosal & yes & A2 & 30 & 0 & 0 & 1 \\
\hline 9 & 54 & MCA & no & M1 & 2 & 0 & 1 & 1 \\
\hline 10 & 47 & MCA & no & M1 & 4 & 0 & 0 & 1 \\
\hline 11 & 54 & PcoA & yes & ICA & 5 & 0 & 0 & 1 \\
\hline 12 & 38 & PcoA & no & CID & 5 & 0 & 0 & 1 \\
\hline 13 & 52 & MCA & no & M1 and 2 M2 & 30 & 0 & 0 & 1 \\
\hline 14 & 61 & $\begin{array}{l}\text { ICA } \\
\text { bifurcation }\end{array}$ & no & ICA post-Pcom & 8 & 0 & 0 & 1 \\
\hline 15 & 36 & MCA & yes & M1 & 10 & 0 & 0 & 1 \\
\hline 16 & 47 & AcoA & yes & A1 & 55 & 0 & 0 & 1 \\
\hline 17 & 50 & MCA & yes & M1 & 60 & 0 & 1 & 1 \\
\hline 18 & 44 & AcoA & yes & both A1, both A2 & 22 & 0 & 0 & 1 \\
\hline 19 & 60 & AcoA & yes & A1 & 80 & 0 & 0 & 1 \\
\hline 20 & 21 & AcoA & yes & $\mathrm{A} 1$ & 10 & 0 & 0 & 1 \\
\hline 21 & 41 & MCA & yes & M1 & 18 & 0 & 1 & 1 \\
\hline
\end{tabular}

op, operative.

\section{Discussion}

In a recent article, we evaluated the feasibility and sensitivity of $m E c o G$ recording in intracranial vascular surgery (7). Intraoperative mEcoG was added to scalp EEG to improve overall electrophysiological monitoring and to detect more specific changes, which might elude detection by standard scalp EEG recording. In the current study, we selected a subgroup of patients who had only intracranial aneurysms in order to have a uniform group. The earliest EEG changes noted were the appearance of HF- $\beta 3$ waves, followed by prolonged arterial occlusion by delta waves and, sometimes, focal burst suppression pattern. Based on these data, we suggest that the appearance of electrophysiological changes could be an indicator for the necessity of brain reperfusion during temporary clipping.

The high sensitivity of $\mathrm{mEcoG}$ can be attributed to several factors as shown in our previous study: the multilobar recording technique, which monitors the lobes corresponding to the vascular territories at risk; the cortical location of the 
Clip Removal; Correlated With Postoperative Neurological and Radiological Status and Outcome

\begin{tabular}{|c|c|c|c|c|c|c|c|}
\hline $\begin{array}{c}\text { EcoG delta } \\
\text { waves after temporary } \\
\text { clipping }\end{array}$ & $\begin{array}{c}\text { EcoG focal } \\
\text { burst after } \\
\text { temporary clip }\end{array}$ & $\begin{array}{c}\text { Scalp EEG } \\
\text { after temporary } \\
\text { clip }\end{array}$ & $\begin{array}{c}\text { Clip removal } \\
\text { EcoG }\end{array}$ & $\begin{array}{c}\text { Clip removal } \\
\text { scalp EEG }\end{array}$ & $\begin{array}{c}\text { Post-op } \\
\text { neurol exam }\end{array}$ & Post-op CT & $\begin{array}{c}\text { Outcome } \\
\text { (GOS) }\end{array}$ \\
\hline 1 & 0 & 0 & 0 & 0 & unchanged & $\begin{array}{l}\text { no related } \\
\text { ischemia }\end{array}$ & 5 \\
\hline 1 & 1 & 0 & 1 & 1 & unchanged & $\begin{array}{l}\text { no related } \\
\text { ischemia }\end{array}$ & 5 \\
\hline 0 & 0 & 0 & 0 & 0 & unchanged & $\begin{array}{l}\text { no related } \\
\text { ischemia }\end{array}$ & 5 \\
\hline 1 & 0 & 0 & 1 & 0 & ubchanged & $\begin{array}{l}\text { no related } \\
\text { ischemia }\end{array}$ & 5 \\
\hline 1 & 1 & 1 & 0 & 0 & unchanged & $\begin{array}{l}\text { no related } \\
\text { ischemia }\end{array}$ & 5 \\
\hline 0 & 0 & 0 & 0 & 0 & unchanged & $\begin{array}{l}\text { no related } \\
\text { ischemia }\end{array}$ & 5 \\
\hline 1 & 1 & 0 & 1 & 0 & Hemiparesis & $\begin{array}{l}\text { Internal capsula } \\
\text { ischemia }\end{array}$ & 3 \\
\hline 1 & 0 & 0 & 1 & 0 & unchanged & $\begin{array}{l}\text { medial } \\
\text { frontobasal } \\
\text { ischemia }\end{array}$ & 5 \\
\hline 1 & 0 & 0 & 0 & 0 & unchanged & $\begin{array}{l}\text { no related } \\
\text { ischemia }\end{array}$ & 5 \\
\hline 0 & 0 & 0 & 0 & 0 & unchanged & $\begin{array}{l}\text { no related } \\
\text { ischemia }\end{array}$ & 5 \\
\hline 1 & 1 & 0 & 1 & 0 & $\begin{array}{l}\text { Hemiplegia } \\
\text { (unchanged) }\end{array}$ & $\begin{array}{l}\text { no related } \\
\text { ischemia }\end{array}$ & 3 \\
\hline 1 & 0 & 0 & 0 & 0 & unchanged & $\begin{array}{l}\text { no related } \\
\text { ischemia }\end{array}$ & 5 \\
\hline 1 & 1 & 0 & 0 & 0 & unchanged & $\begin{array}{l}\text { no related } \\
\text { ischemia }\end{array}$ & 5 \\
\hline 1 & 1 & 0 & 1 & 0 & $\begin{array}{l}\text { Hemiparesis } \\
\text { and aphasia }\end{array}$ & $\begin{array}{l}\text { internal capsul } \\
\text { ischemia }\end{array}$ & 5 \\
\hline 0 & 0 & 1 & 0 & 0 & unchanged & $\begin{array}{l}\text { no related } \\
\text { ischemia }\end{array}$ & \\
\hline 1 & 1 & 0 & 1 & 0 & $\begin{array}{l}\text { anterograde } \\
\text { amnesia }\end{array}$ & $\begin{array}{l}\text { caudate and } \\
\text { frontal ischemia }\end{array}$ & 4 \\
\hline 1 & 1 & 0 & 1 & 0 & Unchanged & $\begin{array}{l}\text { frontotemporal } \\
\text { ischemia }\end{array}$ & 1 \\
\hline 1 & 1 & 0 & 0 & 0 & unchanged & $\begin{array}{l}\text { no related } \\
\text { ischemia }\end{array}$ & 5 \\
\hline 1 & 0 & 0 & 1 & 0 & unchanged & $\begin{array}{l}\text { frontal } \\
\text { hypodensity }\end{array}$ & 5 \\
\hline 1 & 0 & 0 & 0 & 0 & unchanged & $\begin{array}{l}\text { no related } \\
\text { ischemia }\end{array}$ & 5 \\
\hline 1 & 1 & 0 & 0 & 0 & unchanged & $\begin{array}{l}\text { no related } \\
\text { ischemia }\end{array}$ & 5 \\
\hline
\end{tabular}

electrodes closer to the threatened parenchyma; and the elimination of bone and scalp filter.

The correlation between the temporary clipping and the EEG pattern changes observed on mEcoG and scalp EEG has shown that $m E c o G$ is more sensitive than scalp EEG, as it detects earlier and more focal electrophysiological abnormalities (7). Temporary clipping was associated with the appearance of $\mathrm{mEcoG}$ changes including HF- $\beta 3$ waves, delta waves, and focal burst suppression pattern.
The purpose of the current study was to correlate these electrophysiological changes with the immediate postoperative neurological examination and the radiological findings. When HF- $\beta 3$ waves appeared after temporary clipping and progressed to delta waves, but there was no focal burst pattern, we did not observe new neurological deficit. None of the seven patients in this subgroup presented new deficits.

If there is a progression to focal burst suppression pattern (as in eight patients), there is a high risk for persistence of this 
Table 2

Summary of Electrophysiological Signal Recording During Surgery in Two Groups

\begin{tabular}{lcc}
\hline Electrophysiological changes & $m E c o G$ & Scalp EEG \\
\hline HF alone & 19 & 0 \\
HF and delta waves & 17 & 0 \\
HF + delta + burst suppression & 10 & 2 (very late) \\
\hline
\end{tabular}

Table 3

Patient Outcomes

\begin{tabular}{lc}
\hline $\begin{array}{l}\text { Glasgow Outcome } \\
\text { Scale score (19) }\end{array}$ & $\begin{array}{c}\text { Number of patient } \\
\text { (at 3 months) }\end{array}$ \\
\hline V & 16 \\
IV & 2 \\
III & 2 \\
II & 0 \\
I & 1 \\
\hline
\end{tabular}

anomaly after clip removal (seven patients). In these cases, there is similarly a high likelihood of new neurological deficit or new hypodensity on CT (six out of seven patients presented with new findings [85\%]).

Our study was not designed with an interactive strategy; however, based on our results, the transition from HF waves to delta waves, and especially to focal burst suppression pattern, could be an indicator of cerebral threatening ischemia and necessitate brain reperfusion. The clip removal, at this point in time, should lead to the disappearance of abnormal mEcoG patterns. Conversely, the appearance of focal burst patterns that persist after clip removal yields irreversible damage.

We hypothesize that the combination of HF- $\beta 3$ waves followed by delta waves seen on $\mathrm{mEcoG}$ may indicate a threatening hypoperfusion. In our previous study (7), we described these waves, which are characterized by a "spindle-like pattern" in a range of frequency between 23 and $37 \mathrm{~Hz}$. Their origin may reflect the transition between an aerobic and anaerobic state of metabolism. Ischemia in vitro induces a biphasic neuronal response consisting first of cell hyperpolarization owing to potassium channel activation (20), rapidly followed in minutes by cell depolarization owing to the fall of ATP-dependent ionic transporters (21), similar to the cell spiking and $20-40 \mathrm{~Hz}$ network oscillation that accompanies anoxic depolarization. Based on the above and the physiopathology described in our methodological paper (7), we hypothesize that the HF- $\beta 3$ waves observed minutes after temporary clipping may represent the electrophysiological correlates of the anoxia-induced oscillation. One could then assume that as long as HF- $\beta 3$ waves are the only observed changes, the vascular territory tolerates the temporary reduction of blood flow, whereas, conversely, the same territory will suffer if HF- $\beta 3$ waves develop to delta or focal burst suppression patterns, which correlate with anaerobic metabolism. This could explain why all our patients with new deficits or new lesions had focal burst suppression pattern on $\mathrm{mEcoG}$.

It is important to note that three of the strokes were in the subcortical regions, which were not directly monitored by the cortical strip. In fact, the anomalies seen on mECOG reflect the sufferance of the whole underlying brain, which was very sensitive to haemodynamic changes induced by the temporary clipping. Although it is classically admitted that surface EEG does not reflect the activity of deep brain regions such as the thalamus because of concentric dipole orientation, one can assume that cortical region activity is influenced by modification of deep brain structures state as observed by $\mathrm{O}^{\prime}$ Connor (22). This mechanism could explain why, in certain cases, mEcoG abnormalities were associated with deep-seated lesions rather than cortical lesions.

\section{Limitations}

This study was performed with a small group of patients with ruptured and unruptured aneurysms, and with variable clinical grade, aneurysm complexity, and postoperative complications. It is difficult to judge the real clinical value of $\mathrm{mEcoG}$ monitoring on the basis of this limited experience. Moreover, the resolution of focal CT hypodense lesions in patients with SAH has been described (23), and one can assume that the hypodensities seen in our patients CT were not necessarily infarcted regions.

The additional information provided by $\mathrm{mEcoG}$ monitoring can help neurosurgeons avert postoperative complications. The benefits of $\mathrm{mEcoG}$ monitoring could be quantified only in a larger group of patient. In our opinion, however, this initial experience justifies a wider application of $\mathrm{mEcoG}$ monitoring in routine intracranial vascular surgery and especially anterior circulation aneurysms.

\section{Other Techniques}

Quinones-Hinojosa et al. used MEPs in a group of 30 patients harboring basilar tip aneurysms to assess the integrity of perforating arteries supplying the posterior limb of the internal capsule and midbrain and to detect critical ischemia in those areas (10). They found MEP changes that returned to baseline values after corrective measures in five cases, whereas SSEP had shown signal changes in only one case. They concluded that MEPs are more sensitive than SSEP and useful in surgical decision making; however, none of their patients with neurological deficit showed MEP anomalies at the end of the procedure. A Japanese group assessed the utility of MEP in evaluation of anterior choroidal artery territory during intracranial aneurysm surgery in 108 patients (11). In 15 cases, they had transient MEP changes without clinical sign, in 4 cases they showed a correlation between transient hemiparesis and transient MEP changes, and in only 1 case they observed complete hemiplegia, which was associated with the disappearance of MEP. Although the observation and conclusion seem rational, there were many false positive MEP changes with regards to the motor impairment. Neuloh and Schramm showed that MEPs are more sensitive than SSEPs and micro Doppler recording in detecting motor impairment caused by vessel or perforator occlusion in a series of 95 patients with intracranial aneurysms (12). SSEPs were recorded intraoperatively in 76 patients with 79 aneurysms to evaluate the effect of temporary clipping on monitoring. It was concluded that there is no genuinely safe permissible occlusion time. Despite complete recovery of SSEPs after a loss of potential in all cases with 
Table 4

Comparison of Each Group With Regards to the mEcoG Findings

\begin{tabular}{lcc}
\hline & Group A & Group B \\
\hline $\begin{array}{l}\text { Number } \\
\text { Baseline anomalies owing to initial cerebral insult }\end{array}$ & 6 & 15 \\
$\quad$ or pharmacological reasons & 2 & 4 \\
HF- $\beta$ 3 waves & 4 (pharmocologically induced in 2) & 15 \\
HF- $\beta$ 3 waves and delta waves & 4 (pharmocologically induced in 2) & 12 \\
HF- $\beta$ 3, delta, and burst suppression & 2 & 8 \\
$\begin{array}{l}\text { Persistence of anomalies at the end of the } \\
\text { procedure (or after clip removal for group B) }\end{array}$ & 2 (same as baseline) & 7 (one owing to the initial cerebral \\
New neurological deficit or CT hypodensity & & insult and 6 were new findings) \\
\end{tabular}

temporary interruption of circulation, the patient may develop new deficits (24). Thus, the study showed the limitation of SSEP in this instance. Despite the previously mentioned results of MEP and SSEP monitoring, the positive impact of this technique on patients' clinical outcome needs to be studied in a prospective and randomized manner. Martin et al. reported on a series of 18 patients with surgery for intracranial aneurysms using mEcoG, SSEP, and scalp EEG and they concluded that $\mathrm{mEcoG}$ is more sensitive than either scalp EEG or SSEP (15). The sensitivity and specifity of EcoG in the detection of cerebral ischemia could be enhanced with simultaneous monitoring of MEPs or SSEPs.

\section{Conclusion}

The mEcoG is easy to perform and warrants wider application in intracranial vascular surgery to quantify the prevention of postoperative neurological deficit and the improvement in patient outcomes. The $\mathrm{mEcoG}$ abnormalities observed during temporary clipping could be a reliable indicator of the severity of cerebral hypoperfusion, particularly the focal burst suppression pattern. The appearance and persistence of $\mathrm{mEcoG}$ anomalies such as focal burst pattern correlates with new neurological deficit and new hypodensity on CT and could be an indicator of threatening cerebral ischemia. Future studies may provide additional information on the real clinical value of this technique in routine intracranial vascular surgery.

\section{Acknowledgments}

This study was supported by a grant to L.R. from Leenaards foundation, Lausanne, Switzerland.

\section{References}

1. Little JR, Lesser RP, Luders H. Electrophysiological monitoring during basilar aneurysm operation. Neurosurgery 1987;20(3): 421-426.

2. Ulbert I, Halgren E, Heit G, Karmos G. Multiple microelectroderecording system for human intracortical applications. J Neurosci Methods 2001;106:69-79.

3. Nuwer MR, Daube J, Fischer C, Schramm J, Yingling CD. Neuromonitoring during surgery. Report of an IFCN committee. Electroencephalogr Clin Neurophysiol 1993;87:263-276.

4. Huotari AM, Koskinen M, Suominen K, et al. Evoked EEG patterns during burst suppression with propofol. Br J Anesth 2004;92(1):18-24.

5. Lopez JR, Chang SD, Steinberg GK. The use of electrophysiological monitoring in the intra-operative management of i. c. aneurysms. J Neurol Neurosurg Psych 1999;66:189-196.
6. Mooij JA, Buchthal A, Belopavlovic M. Somatosensory evoked potential monitoring of temporary middle cerebral artery occlusion during aneurysm operation. Neurosurgery 1987;21: 492-496.

7. Debatisse D, Pralong E, Dehdashti AR, Regli L. Simultaneous multilobar electrocorticography ( $\mathrm{mEcoG})$ and scalp electroencephalography (scalp EEG) during intracranial vascular surgery: a new approach in neuromonitoring. Clin Neurophysiol 2005;116(12):2734-2740.

8. Emerson RG, Turner CA. Monitoring during supratentorial surgery. J Clin Neurophys 1993;10:404-411.

9. Mizoi K, Yoshimoto T. Permissible temporary occlusion time in aneurysm surgery as evaluated by evoked potential monitoring. Neurosurgery 1993;33:434-440.

10. Quinones-Hinojosa A, Alam M, Loyn R, Yingling CD, Lawton MT. Transcranial motor evoked potentials during basilar artery aneurysm surgery: Technique application for 30 consecutive patients. Neurosurgery 2004;54:916-924.

11. Suzuki K, Kodama N, Sasaki T, et al. Intraoperative monitoring of blood flow insufficiency in the anterior choroidal artery during aneurysm surgery. J Neurosurg 2003;98(3):507-514.

12. Neuloh $G$, Schramm J. Monitoring of motor evoked potentials compared with somatosensory evoked potentials and microvascular Doppler US in cerebral aneurysm surgery. J Neurosurg 2004;100(3):389-399.

13. Jones T, Chiappa K, Young RR, Ojemann RG, Crowell RM. EEG monitoring for induced hypotension for surgery of intracranial aneurysms. Stroke 1979;10(3):292-294.

14. Nuwer MR, Comi G, Emerson R. IFCN standards for digital recording of clinical EEG. Electroencephalogr Clin Neurophysiol 1998;106:259-261.

15. Martin CJ, Sinson G, Patterson T, Zager EL, Stecker MM. Sensitivity of scalp EEG, cortical EEG and somatosensory evoked responses during surgery for intracranial aneurysms. Surg Neurol 2002;58:317-321.

16. Friedman WA, Chadwick GM, Verhoeven FJS, Mahla M, Day AL. Monitoring of somatosensory evoked potentials during surgery for middle cerebral artery aneurysms. Neurosurgery 1991;29: $83-88$.

17. Friedman WA, Kaplan BL, Day AL, Sypert GW, Curran MT. Evoked potential monitoring during aneurysm operation: observations after fifty cases. Neurosurgery 1987;20:678-687.

18. Krieger D, Adams HP, Albert DIMF, Haken MV, Hacke W. Pure motor hemiparesis with stable somatosensory evoked potential monitoring during aneurysm surgery: case report. Neurosurgery 1992;31:145-150.

19. Jennet B, Bond M. Assessment of outcome after severe brain damage. Lancet 1975;i:480-484.

20. Fujimura N, Tanaka E, Yamamoto S, Shigemori M, Hiogashi H. Contribution of ATP-sensitive potassium channels to hypoxic hyperpolarization in rat hippocampal CA1 neurons in vitro. J Neurophysiol 1997;77:378-385. 
21. Muller $\mathrm{M}$, Somjen GG. $\mathrm{Na}(+)$ and $\mathrm{K}(+)$ concentrations, extraand intracellular voltages, and the effect of TTX in hypoxic rat hippocampal slices. J Neurophysiol 2000;83:735-745.

22. O'Connor SC, Robinson PA. Analysis of the electroencephalographic activity associated with thalamic tumors. J Theor Biol 2005;233(2):271-286.
23. Baker CJ, Ortiz O, Solomon RA. Resolution of CT hypodense lesions in patients with subarachnoid hemorrhage. Surg Neurol 1993;39:158-162.

24. Schick U, Dohnert J, Meyer JJ, Vitzthum HE. Effects of temporary clips on somatosensory evoked potentials in aneurysm surgery. Neurocrit Care 2005;2(2):141-149. 